\title{
Education Program for Diabetic Elderly Patients About Subcutaneous Injection and Blood Sugar Test
}

\author{
${ }^{1}$ Mervat Abd El-Kader Ahmad Mohamed \& ${ }^{2}$ Amal Abd El-Azem Mohamed \\ ${ }^{1}$ Lecturer of Community Health Nursing, Faculty of Nursing, Beni- Suef University \\ 2 Technical Nursing, Beni- Suef University
}

\begin{abstract}
The goal of gerontology is not only to determine ways of prolonging life but also to improve the quality of care for the older persons and to ensure that they will become active and productive personnel. The administration of subcutaneous injection (SC) is used when there is a need for medication to be absorbed more slowly and have prolonged effect as for insulin. Blood sugar test is important method to measure and follow level the sugar of the blood.

Aim of this study was to assess the effect of an educational program for diabetic elderly patients about subcutaneous injection and blood sugar test.

Sample: The present study included all diabetic elderly patients in Geriatric Home and Geriatric Club in Beni- Suef city. The research design was a quasi-experimental one with pre, post and follow-up tests. Tools: The investigators used three tools for data collection; tool I: A structured knowledge test, tool II: The observation checklist sheet, and tool III: A structured attitudes' sheet. Results: the study results showed that, more than three quarters were range from 60 to less than 65 years, while less than one fifth were from 65: < 70 years, all of them never attended any previous training program. There are highly statically significant differences in the studied sample practices of these measures between pretest and immediate post-test and also between pretest and late follow-up test. Conclusion: Before the educational program the majority of the studied sample had poor knowledge related to subcutaneous injection and sugar blood test. The studied sample knowledge and skills in the field of the elderly care improved immediately after exposure to the educational program, while after four months their knowledge declined. Recommendations; Developing planning, and implementing a training program related the elders' care needs for non paramedical personnel for improving health care outcomes.

Keys words: Education program, diabetic elderly patient, subcutaneous injection, and sugar blood test.
\end{abstract}

\section{Introduction:}

Ageism is a term used to describe discrimination against the older people. It can interfere with effective practice and prevent the kind of comprehensive and interdisciplinary service, aging person needs and deserves. ${ }^{(1)}$ The wellness among the older population varies considerably, it is influenced by many factors, including personality traits, life experiences, current physical health, and current societal supports. Some elderly people demonstrate maximum adaptability, resourcefulness, optimism, and activity so, healthy aging means being able to function, even when disabled, with a minimum of ordinary help from others. ${ }^{(2)}$

The total population in 2006 reached 6.5 billion. The older population persons, 65 years or older, were 200 millions in 1950. Then, they were increased to 482 million (7.4\% from the total population) in 2006. The central Intelligence Agency (2007) reported that; in 2020 one billion of world population will be older adults and $60.0 \%$ of diabetic patients live in developing countries ${ }^{(3)}$

The administration of subcutaneous injection (SC) is used when there is a need for medication to be absorbed more slowly and have prolonged effect as for insulin. ${ }^{(4) \&(5)}$ . Five percent of the entire populations have diabetes; $20.0 \%$ of all diabetics are 60 years 
or older ${ }^{(6)}$

Diabetes mellitus, affecting 10 million Americans; and thyroid disease, affecting up to one third of the older US citizens; are the two most prevalent endocrine disorders. Diabetes of the old adult onset can be linked with hyperinsulinemia, obesity, and hypertension, and is important to diagnose and control, either with diet, oral hypoglycemia agents, or insulin. ${ }^{(7)}$

In demographic terms, diabetes mellitus was the third largest country in the Middle East after Turkey and Iran. ${ }^{(8)}$ In 2010, Egypt's population was more than 76.9 million, making it the most populous Arab country, with more than $24 \%$ of the Arab world's population. Diabetes mellitus affects approximately $8 \%$ of persons over the age of 65 years and more than $20 \%$ of those over age 80.(7) . Statistics from the Egyptian Ministry of Health show that with year 2020 diabetes mellitus will increase in the Egyptian life expectancy ${ }^{(9)}$.

The rapidly growing number of the elderly clients facing the challenges of normal aging, ${ }^{(10)}$ which is frequently, accompanied by chronic illness, progressive disability, and limited personal and community supports. ${ }^{(11)}$. The goal of gerontology is not only to determine ways of prolonging life but also to improve the quality of care for the older persons and to ensure that they will become active and productive personnel ${ }^{(12)}$.

Nursing has vital interventions with diabetic geriatric patient; as "evaluate the patient's feelings about his/her illness and determine his/ her level of knowledge and expectations," perform comfort measures to promote relaxation and relieve anxiety", monitor the patient's weight, and assess the patient and family coping. ${ }^{(13)}$

\section{Significance of the study}

In Egypt; diabetes mellitus affects approximately $8 \%$ of persons over the age of 65 years and more than $20 \%$ of those over age $80 .{ }^{(7)}$. Statistics from the Egyptian Ministry of Health show that with year 2020 diabetes mellitus will increase in the Egyptian life expectancy ${ }^{(9)}$.

\section{Aims of the study:}

The study was carried out with the aim to assess the effect of the educational program for diabetic elderly patients about subcutaneous injection and blood sugar test.

\section{Study Design:}

A quasi-experimental design was applied with pre, post and follow-up tests.

\section{Research Hypothesis:}

The educational programs will affect and improve the practices and attitudes of diabetic elderly patients regarding the program items.

\section{Setting:}

Beni Suief government have only one geriatric home and one a geriatric club. The present study was carried out over 10 months (beginning in July 2012 ending in April 2013) at a geriatric home and a geriatric club in Beni Suief city, Upper Egypt.

\section{Study Sample:}

A purposive sample was recruited, including all diabetic geriatric clients (58) of both male and female gender from the total number (107) of a geriatric client at geriatric home and club in Beni- Suief city.

\section{Inclusion criteria:}

All diabetic geriatric clients oriented, educated, and present during the study period and willing to participate in the study.

\section{Exclusion criteria:}

Healthy geriatric clients, disoriented comatose, illiterate, who refuse to participate in the study or not present during study period.

\section{Data collection tools:}

\section{Tool I:}

A structured knowledge sheet was designed by the researchers to assess the study sample knowledge before application of the program, immediately after the program and in the follow-up after 4 months, to evaluate the cognitive domain. This 
questionnaire includes 9 questions about the socio-demographic data of the studied sample and 9 questions about assessment knowledge as follows:

1- Socio-demographic characteristics of the studied sample, which includes: Personal and social data such as age, sex, level of education, occupational status, and previous training program attended.

2-Assessment of the geriatric persons' knowledge about handling the following: measuring blood sugar test and administration of insulin drugs by subcutaneous injection route. The sheets were prepared by the first researcher.

\section{Tool II:}

The observation checklist sheet was developed by the first researcher to assess the studied sample' handling related to the two items before application of the program (pretest), and immediately (post-test). After 4 months from the program implementation a follow-up-test was done. This is to evaluate the psychomotor domain, the evaluation of the studied sample' handling was done through demonstration between the learners.

\section{Scoring system used for tool I \& II:}

States of our studied sample knowledge and skills in the pretest, immediate post-test, and in late follow-up test were judged based on Kotb, 2004 and Sharkawy, 2007 who estimated the answers by taking points as the following: Poor $=<$ $50 \%$, Satisfactory $=50 \%$, and Good $=>$ $+70 \%$. ${ }^{(14) \&(15)}$

\section{Tool III:}

A structured attitude sheet was designed by the researchers to assess the studied sample attitudes toward the different program items before application of the program, immediately after the program and after 4 months. This was done to evaluate the effective domain. To measure their attitudes toward the items of the fourteen SelfInstruction Units regarding the elders' care that was listed in the educational program. The modified Kerrick (1969) attitude Scale was adopted, it includes five grades extremely important, very important, important, slightly important, and not important. The score weight is $5,4,3,2$, and 1. This technique can be used to score: The attitudes of one individual toward one single item or more, and the attitudes of a group of individuals toward one single item or more (16).

This evaluation was based on findings whether there is a difference between pretest, immediate post-test, and late follow-up test or not handling measuring all sheet items and methods" for the studied sample involved in the program as well as the effect of the program on their practices.

Content validity of tools: The content validity of the tools were revised by a panel of experts in nursing and medicine to ascertain its comprehensiveness and its content validity and according to their review few modifications were carried out on the content field work.

\section{Analysis of resources:}

Several visits were carried out to the different departments of the geriatric home and club in Beni Suef governorate. The objectives and aims of the educational program were: firstly to make the directors of each involved department aware, its strategies and effect on the diabetic geriatric patients' knowledge and competencies. Secondly, it was important to have a feedback from these administrative key personnel about the overview plan. Thirdly, it was important to have their full support and cooperation as well as permission for involved personnel to attend the program. During the visits, it was important to select a suitable place for running the program to find out if the educational media are available and if possible to have any assistance during the training.

\section{Administrative and ethical considerations:}

Before conducting the study official letters issued from the Dean of the Faculty of Nursing in Beni Suef University were forwarded to the directors of the Geriatric 
Home and Geriatric Club in Beni Suef Governorate. Then, approvals were obtained for accomplishing this program. The researchers took oral permissions from the geriatric personnel who agreed to participate in this educational program and they appreciated the positive approach.

Review of the literature including periodicals, geriatric textbooks, special articles published by Egyptian authors as well as the internet search were used to be acquainted bout the topic and to develop the tools. Before starting data collection and applying the program, the investigators explained the purpose of the research to keep it clear and get their cooperation.

\section{Preparation of teaching aids:}

To help and facilitate teaching to geriatric personnel, it was important for implementing the program to use audiovisual aids such as; wall-chart, dolls, posters, transparencies, blackboard, chalk, and projector; Equipment for injection, sterile syringe and needle, medication cards, ampoules or vial containing medications, solvent (e.g. normal saline or sterile water), alcohol swab, dry sponge, tray, file, container for disposing of waste product and disposable gloves. The investigators used role-play by the participants themselves to demonstrate certain procedures.

\section{Pilot study:}

A pilot study was carried out before starting data collection on 10 geriatric personnel, who were excluded from the study. Data obtained were analyzed manually. The aim of the pilot study was to test the clear-ability, measurably, reliability and validity of the study' tools. The clarity of the wording as well as the time needed to fulfill each questionnaires and observation checklist. The necessary modifications were done to reach the final form.

\section{Developing the educational program:}

Preparation and finish the educational program needs 10 months (beginning in July 2012 ending in April 2013) at Geriatric Home and Geriatric Club in Beni Suef City -Upper Egypt. Preparation of the program, pre test, education phases and immediate test started in July 2012 to end in April 2013. The investigators prepared the two lectures (theory, and clinical / practical demonstration) for the program course, distributed as the following: the 1st group in Geriatric Home for 12 weeks and the 2nd group in Geriatric Club for another 12 weeks to collect data and develop the educational program. The investigators were available from $9.00 \mathrm{am}$ to $1.00 \mathrm{pm}$ during 2 days weekly.

Before starting the educational program, the investigators explained the aim and procedures of the study to participants (theory \& clinical/ practical) and handled them handouts. With the end of the programs, the immediate post- test was done.

\section{Implementation of the program:-}

1- During the application of this program, the educator repeated instructions, asked learners to repeat the learned procedures, and intensified extracurricular activities. The researchers were been that; the group discussion be carried out in a friendly atmosphere with no rigidity, and flexibility was ensured.

2- More time was given to those who had problems in applying the learned educational experiences and in achieving objectives whether these were cognitive, psychomotor or affective.

3- Implementation of this program was composed of two parts; the curriculum organization, and the curriculum specification.

\section{Evaluation the program:-}

Four months after the program implementation (end of April 2013), the follow-up test was done to participants. 


\section{Statistical analysis:}

Collected data were coded and verified prior to computerized data entry. The statistical package of social science (SPSS), version 10 for windows was used for data entry and analysis. Descriptive statistics were calculated i.e. frequency, percentage, mean, standard deviation, Chi square test and t-test. $\mathrm{P}$-value less than 0.01 was considered as highly statistically significant, while P-value less than 0.05 was considered as statistically significant ${ }^{(17)}$.

\section{Results:}

Table (1) shows the percentage distribution of the studied sample regarding their socio-demographic characteristics. As for age nearly $80 \%$ of the studied sample was from 60 to less than 65 years, while less than one fifth $(17.2 \%)$ had 65 to less than 70 years, and a minority $(3.5 \%)$ had 70 years or more. As regards their gender, most of them $(94.8 \%)$ were males and only $5.2 \%$ were females. Concerning their qualification, about three quarters of them $(75.9 \%)$ graduated from the faculty, while only $24.1 \%$ of them were secondary or technical education levels. Regarding to their marital status, about two thirds of them $(67.3 \%)$ were single, while around one third $(31.0 \%)$ were married and the rest of them $(1.7 \%)$ were divorced. As regards their occupational status, more than three quarters of them $(77.6 \%)$ was haven't job, while less than one quarter $(22.4 \%)$ have a job. All of them had never attended previous training programs.

Table (2): Reveals the distribution of the scores obtained by the studied sample' concerning and the results of their measuring sugar blood test. Before exposure to the showed program that most of the studied had poor scores towards; prepare equipment, know percussion methods, and know ideal steps, used percussion methods, and applying / measuring sugar blood test $(94.8 \%, 91.4 \%$, $94.8 \%, 96.6 \%, \& 91.4 \%$ respectively).
Table (1): Percentage distribution of the studied sample regarding their sociodemographic characteristics $(n=58)$

\begin{tabular}{|c|c|c|}
\hline Items & No & $\%$ \\
\hline \multicolumn{3}{|l|}{ Age: } \\
\hline$-60-<65$ & 46 & 79.3 \\
\hline$\square 65-<70$ & 10 & 17.2 \\
\hline 口 $70+$ & 2 & 3.5 \\
\hline \multicolumn{3}{|l|}{ gender: } \\
\hline${ }^{\circ}$ Female & 3 & 5.2 \\
\hline 口 Male & 55 & 94.8 \\
\hline \multicolumn{3}{|l|}{ - Level of education: } \\
\hline${ }^{\circ}$ Faculty education & 44 & 75.9 \\
\hline $\begin{array}{l}\text { Secondary or } \\
\text { Technical } \\
\text { (Diploma) }\end{array}$ & 14 & 24.1 \\
\hline \multicolumn{3}{|l|}{ - Marital status: } \\
\hline Single & 39 & 67.3 \\
\hline Married & 18 & 31.0 \\
\hline 口 Divorced & 1 & 1.7 \\
\hline \multicolumn{3}{|l|}{$\begin{array}{l}\text { - Occupational } \\
\text { status: }\end{array}$} \\
\hline${ }^{\circ}$ No job & 45 & 77.6 \\
\hline - have job & 13 & 22.4 \\
\hline \multicolumn{3}{|l|}{$\begin{array}{l}\text { - Attendance of } \\
\text { training programs }\end{array}$} \\
\hline 口 Yes & -- & -- \\
\hline - No & 58 & 100 \\
\hline
\end{tabular}

After the program at immediate posttest, the majority of them had a good score $(96.6 \%, 86.2 \%, 70.7 \%, 91.4 \%, \& 86.3 \%)$ for the same five items respectively. While after four months at late follow-up test, their practices dropped to $(51.8 \%, 72.4 \%, 8.7 \%$, $8.7 \%$, \& $44.9 \%$ ) of them had a good score respectively.

The same table reveals highly statistically significant differences in the studied sample practices of these measures between pretest and immediate post-test (P1 $<0.01)$, and also between pretest and late follow-up test $(\mathrm{P} 2<0.01)$ in all items.

Table (3) displays the distribution of the scores obtained by the studied sample 
Table (2) Percentage distribution of the scores obtained by the studied sample concerning sugar blood test at pre, post, \& follow-up tests $(n=58)$

\begin{tabular}{|c|c|c|c|c|c|c|c|c|}
\hline Test & \multicolumn{2}{|c|}{ Pretest } & \multicolumn{2}{|c|}{ Post-test } & \multicolumn{2}{|c|}{$\begin{array}{c}\text { Follow-up } \\
\text { test }\end{array}$} & \multirow{2}{*}{$\frac{\mathrm{X}^{1}}{(\mathrm{P} 1)}$} & \multirow{2}{*}{$\frac{\mathrm{X}^{2}}{(\mathbf{P} 2)}$} \\
\hline No. & No. & $\%$ & No. & $\%$ & No. & $\%$ & & \\
\hline \multicolumn{9}{|l|}{ 1- Prepare equipment. } \\
\hline - Poor & 55 & 94.8 & - & - & 6 & 10.3 & \multirow{3}{*}{$\begin{array}{l}108.07 \\
(0.00)\end{array}$} & \multirow{3}{*}{$\begin{array}{c}83.16 \\
(0.00)\end{array}$} \\
\hline - Satisfactory & 2 & 3.4 & 2 & 3.4 & 22 & 37.9 & & \\
\hline - Good & 1 & 1.7 & 56 & 96.6 & 30 & 51.8 & & \\
\hline Mean \pm SD & \multicolumn{2}{|c|}{$0.86 \pm 1.66$} & \multicolumn{2}{|c|}{$9.33 \pm 1.32$} & \multicolumn{2}{|c|}{$6.34 \pm 1.22$} & & \\
\hline \multicolumn{9}{|l|}{ 2- Know percussion methods } \\
\hline - Poor & 53 & 91.4 & - & - & - & - & \multirow{3}{*}{$\begin{array}{l}103.69 \\
(0.00)\end{array}$} & \multirow{3}{*}{$\begin{array}{l}100.76 \\
(0.00)\end{array}$} \\
\hline - Satisfactory & 5 & 8.6 & 8 & 13.8 & 16 & 27.6 & & \\
\hline - Good & - & - & 50 & 86.2 & 42 & 72.4 & & \\
\hline Mean \pm SD & \multicolumn{2}{|c|}{$0.72 \pm 1.6$} & \multicolumn{2}{|c|}{$7.47 \pm 0.94$} & \multicolumn{2}{|c|}{$7.172 \pm 1.22$} & & \\
\hline \multicolumn{9}{|l|}{ 3- Know ideal steps } \\
\hline - Poor & 55 & 94.8 & - & - & 30 & 51.7 & \multirow{3}{*}{$\begin{array}{c}105.8 \\
(0.00)\end{array}$} & \multirow{3}{*}{$\begin{array}{c}27.74 \\
(0.00)\end{array}$} \\
\hline - Satisfactory & 3 & 5.2 & 17 & 29.3 & 23 & 39.6 & & \\
\hline - Good & - & - & 41 & 70.7 & 5 & 8.7 & & \\
\hline Mean \pm SD & \multicolumn{2}{|c|}{$0.9 \pm 1.02$} & \multicolumn{2}{|c|}{$6.0 \pm 0.9$} & \multicolumn{2}{|c|}{$3.76 \pm 1.27$} & & \\
\hline \multicolumn{9}{|l|}{ 4- Used percussion methods } \\
\hline - Poor & 56 & 96.6 & - & - & 6 & 10.3 & \multirow{3}{*}{$\begin{array}{l}108.74 \\
(0.00)\end{array}$} & \multirow{3}{*}{$\begin{array}{c}87.07 \\
(0.00)\end{array}$} \\
\hline - Satisfactory & 1 & 1.7 & 5 & 8.6 & 47 & 81 & & \\
\hline - Good & 1 & 1.7 & 53 & 91.4 & 5 & 8.7 & & \\
\hline Mean \pm SD & \multicolumn{2}{|c|}{$0.33 \pm 1.05$} & \multicolumn{2}{|c|}{$5.43 \pm 0.65$} & \multicolumn{2}{|c|}{$3.05 \pm 1.65$} & & \\
\hline \multicolumn{9}{|l|}{ 5- Measuring sugar blood test } \\
\hline - Poor & 53 & 91.4 & 1 & 1.7 & 10 & 17.2 & & \\
\hline - Satisfactory & 5 & 8.6 & 7 & 12 & 22 & 37.9 & 100.41 & 66.05 \\
\hline - Good & - & - & 50 & 86.3 & 26 & 44.9 & $(0.00)$ & $(0.00)$ \\
\hline Mean \pm SD & 1.12 & 1.27 & 6.5 & 1.11 & 5.0 & \pm 1.85 & & \\
\hline
\end{tabular}

$\mathbf{P} \leq \mathbf{0 . 0 1}=$ Highly statistically significant differences.

P1 = Relation between pre-test and immediate post-test

P2 = Relation between pre-test and follow-up test

concerning their practices of subcutaneous injection at pre, post, and follow-up tests. Before the program exposure, most of the study sample had poor information about; know percussion methods, know ideal steps, applying subcutaneous injection, and used percussion methods $(98.3 \%, 98.3 \%, 96.6 \%$, \& $100 \%$ respectively). At immediate post-test after the program, their practices were enhanced to be good score level $(72.4 \%$, $94.8 \%, 86.2 \%, \& 41.4 \%$ ) respectively, while after four months scores dropped $(27.7 \%$,
$55.2 \%, 25.8 \%$ \& $20.7 \%$ respectively. There were statistically highly significant differences between pretest and immediate post-test $(\mathrm{P} 1<0.01)$ and also between pretest and late follow-up test $(\mathrm{P} 2<0.01)$ in all items.

Table (4) shows the percentage distribution of the total scores of the geriatric personnel's attitudes towards the educational program. pretest results, 22.4\%, 36.3\%, $27.6 \%, 10.3 \%, \& 3.4 \%$ were evaluated 
Table (3): Distribution of the scores obtained by the studied sample concerning their practices of subcutaneous injection in pretest, post-test, and follow-up test ( $n=58$ )

\begin{tabular}{|c|c|c|c|c|c|c|c|c|}
\hline \multirow{2}{*}{$\begin{array}{ll} & \text { Test } \\
\text { Items } & \end{array}$} & \multicolumn{2}{|c|}{ Pretest } & \multicolumn{2}{|c|}{ Post-test } & \multicolumn{2}{|c|}{ Follow-up test } & \multirow{2}{*}{$\frac{\mathrm{X}^{1}}{(\mathbf{P 1})}$} & \multirow{2}{*}{$\begin{array}{c}\mathbf{X}^{2} \\
(\mathbf{P} 2) \\
\end{array}$} \\
\hline & No. & $\%$ & No. & $\%$ & No. & $\%$ & & \\
\hline \multicolumn{7}{|l|}{ 1- Know percussion methods } & \multirow{4}{*}{$\begin{array}{r}112.24 \\
(0.00)\end{array}$} & \multirow{4}{*}{$\begin{array}{r}26.18 \\
(0.00)\end{array}$} \\
\hline - Poor & 57 & 98.3 & - & - & 16 & 27.4 & & \\
\hline - Satisfactory & 1 & 1.7 & 16 & 27.6 & 26 & 44.9 & & \\
\hline - Good & - & - & 42 & 72.4 & 16 & 27.7 & & \\
\hline Mean \pm SD & \multicolumn{2}{|c|}{$0.31 \pm 1.01$} & \multicolumn{2}{|c|}{$6.97 \pm 0.9$} & \multicolumn{2}{|c|}{$5.29 \pm 1.87$} & & \\
\hline \multicolumn{3}{|l|}{ 2- Know ideal steps } & & & & & \multirow{4}{*}{$\begin{array}{c}113 \\
(0.00)\end{array}$} & \multirow{4}{*}{$\begin{array}{l}90.48 \\
(0.00)\end{array}$} \\
\hline - Poor & 57 & 98.3 & - & - & 6 & 10.3 & & \\
\hline - Satisfactory & 1 & 1.7 & 3 & 5.2 & 20 & 34.5 & & \\
\hline - Good & - & - & 55 & 94.8 & 32 & 55.2 & & \\
\hline Mean \pm SD & \multicolumn{2}{|c|}{$0.31 \pm 0.99$} & \multicolumn{2}{|c|}{$7.91 \pm 1.06$} & \multicolumn{2}{|c|}{$6.62 \pm 1.78$} & & \\
\hline \multicolumn{3}{|c|}{ 3- Applying subcutaneous injection } & & & & & \multirow{4}{*}{$\begin{array}{l}108.52 \\
(0.00)\end{array}$} & \multirow{4}{*}{$\begin{array}{l}74.43 \\
(0.00)\end{array}$} \\
\hline - Poor & 56 & 96.6 & - & - & 10 & 17.3 & & \\
\hline - Satisfactory & 1 & 1.7 & 8 & 13.8 & 33 & 56.9 & & \\
\hline - Good & 1 & 1.7 & 50 & 86.2 & 15 & 25.8 & & \\
\hline Mean \pm SD & \multicolumn{2}{|c|}{$0.47 \pm 1.56$} & \multicolumn{2}{|c|}{$8.93 \pm 1.21$} & \multicolumn{2}{|c|}{$6.72 \pm 1.33$} & & \\
\hline \multicolumn{3}{|l|}{ 4-Used percussion methods } & & & & & \multirow{4}{*}{$\begin{array}{l}91.02 \\
(0.00)\end{array}$} & \multirow{4}{*}{$\begin{array}{l}50.12 \\
(0.00)\end{array}$} \\
\hline - Poor & 58 & 100 & 7 & 12.1 & 23 & 41.4 & & \\
\hline - Satisfactory & - & - & 27 & 46.5 & 22 & 37.9 & & \\
\hline - Good & - & - & 24 & 41.4 & 13 & 20.7 & & \\
\hline Mean \pm SD & \multicolumn{2}{|c|}{$0.24 \pm 0.73$} & \multicolumn{2}{|c|}{$5.05 \pm 1.15$} & \multicolumn{2}{|c|}{$3.76 \pm 1.74$} & & \\
\hline
\end{tabular}

Table (4): Percentage distribution of the total scores of the studied sample's attitudes toward the educational program at pre, post, and follow-up tests $(n=58)$

\begin{tabular}{|c|c|c|c|c|c|c|c|c|}
\hline \multirow{3}{*}{ 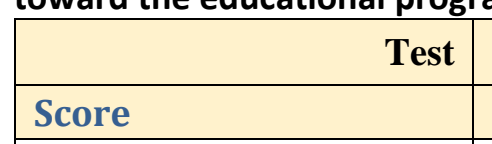 } & \multirow{2}{*}{\multicolumn{2}{|c|}{ Pretest }} & \multirow{2}{*}{\multicolumn{2}{|c|}{ Post-test }} & \multirow{2}{*}{\multicolumn{2}{|c|}{ Follow-up test }} & \multirow{3}{*}{\begin{tabular}{|c|}
$\mathbf{X}^{1}$ \\
$(\mathbf{P 1})$ \\
\end{tabular}} & \multirow{3}{*}{$\begin{array}{c}\mathrm{X}^{2} \\
(\mathbf{P} 2) \\
\end{array}$} \\
\hline & & & & & & & & \\
\hline & No. & $\%$ & No. & $\%$ & No. & $\%$ & & \\
\hline - Extremely important & 13 & 22.4 & 28 & 48.3 & 48 & 82.8 & \multirow{6}{*}{$\begin{array}{c}19.6 \\
(0.00)\end{array}$} & \multirow{6}{*}{$\begin{array}{l}47.99 \\
(0.00)\end{array}$} \\
\hline - Very important & 21 & 36.3 & 25 & 43.1 & 10 & 17.2 & & \\
\hline - Important & 16 & 27.6 & 5 & 8.6 & - & - & & \\
\hline - Slightly important & 6 & 10.3 & - & - & - & - & & \\
\hline - Not important & 2 & 3.4 & - & - & - & - & & \\
\hline Total & 58 & 100 & 58 & 100 & 58 & 100 & & \\
\hline Mean \pm SD & \multicolumn{2}{|c|}{$428.81 \pm 137.30$} & \multicolumn{2}{|c|}{$523.19 \pm 77.02$} & \multicolumn{2}{|c|}{$574.48 \pm 45.34$} & & \\
\hline
\end{tabular}

concerning extremely important, very important, important, slightly important, and not important respectively. At immediate post-test $48.3 \%, 43.1 \%, 8.6 \%, 0.0 \%$, \& $0.0 \%$ related the same items respectively, while at late follow-up test, the majority of them $(82.8 \%)$ had an extremely important score, and only $17.2 \%$ had a very important score. There were highly statistically significant differences between the studied sample's 
attitudes regarding the study program items between pretest and immediate post-test $(\mathrm{X} 1=19.6 \& \mathrm{P} 1<0.01)$ and also between pretest and late follow-up test $(\mathrm{X} 2=47.99 \&$ $\mathrm{P} 2<0.00$.

\section{Discussion:}

Towner, (2006) decided that; the need for primary health care for elderly population increases, knowledge of special characteristics of the older person, as well as demographics of the aging population, resources and the principles of the care are important in the provision of the effective, professional primary health care by advanced practice nurses (18). Also, Meiner, and Lueckenotte, (2006) mentioned that the older adults depend more than younger persons on the health care system to deliver the care that optimizes their health status and functional capabilities. Thus, their quality of life often depends on the type and quality of the primary health care nurses receives ${ }^{(19)}$.

The elderly, like any age group, have certain basic needs, physiologic and safety needs as well as the needs for love and belonging. Self-esteem and self-actualization. Their physical, emotional and social needs are complex and interrelated ${ }^{(1)}$.

The discussion of the results of the current study will emphasize on the elders' knowledge concerning blood sugar test and subcutaneous injection as routes of drug (insulin) which should be done to diabetic elder patients, in addition to their attitudes toward the present program items.

The present study results showed that, nearly three quarters of the studied sample their age was less than 55 years, and all of them had never attended any training program. In disagreement Elkin, et al. (2000) individuals does not adapt to the aging process in social isolation but it should be through their interaction with others.

Moreover, they reported that emotional support and practical assistance emerged as the primary supportive and non-supportive behaviors from others. It is necessary to pay special attention to the importance of psycho geriatric care to help the elderly in the institution to cope and adjust with their aging process and institutionalization. ${ }^{(20)}$

The role of the nurse in maintenance of health and well being in older people is generally supported in a study of Imperial, and Pusey-Reid, (2006) which decided that the understanding of the body functions has long been an interest for all older persons, social support and health care givers. ${ }^{(21)}$

As regards have practices of the blood sugar test, the current study findings indicated that highly statistically significant differences in the entire studied sample' skills between pretest, immediate post-test and at follow-up test $(\mathrm{P} 1, \mathrm{P} 2 \& \mathrm{P} 3<0.01)$. There was a lack of knowledge and practices among the geriatric personnel regarding the elders' measuring sugar blood test. On the same way the study of Sharkawy, (2007) in Assuit which revealed results similar ${ }^{(16)}$.

This study results' revealed illustrated that the majority of the study sample had a poor score for knowledge about subcutaneous injection before the program, while with immediate post-test after the program their practices was enhanced to good score level, and after four months it dropped.

Attitudes are feelings, values, or beliefs about something that determines behavior. If the elderly person has attitude that characterizes older people as less healthy and alert and more dependent, then her own anxiety and fear of personal aging, as well as a lack of knowledge regarding older people, contribute to commonly held negative attitudes, myths, and stereotypes about the older people. ${ }^{(22)}$

The study distribution of the total scores of the studied sample's attitudes toward the educational program before its implementation, pretest reveals that more than one fifth provided score of extremely important, more than one third very important , but a minority not important. Immediately after the implementation of the program at post test, nearly half from them provided score of extremely important and more than two fifths very important, but no one provided any score toward the other items. After four months the majority of the studied 
sample provided score of extremely important, but with very important the score it dropped to less than one fifth, but no one provided any score with the other items. These results indicate that, the program items cover the vital knowledge, which the elderly personnel want to know about it. As well, it reflects their benefits from the program for a long time. The result with Sharkawy, S. A. E. H. (2007) study, which carried out at governmental geriatric homes in Alexandria, while revealed that the nurses' knowledge and practices toward care of the elderly had high grades in their attitudes toward their elders care program in immediate post-test ${ }^{(16)}$.

\section{Related to research aim and the results of the present study, it can be concluded that:}

The majority of the studied sample had poor knowledge and skills regarding Subcutaneous (SC) injection and sugar blood test. Immediately after exposure to the educational program, improved their knowledge and skills, while after four months, their knowledge declined but still remained significantly better than the state before their exposure to the program. The studied sample attitudes toward the elderly care improved between pretest and immediate post-test and improved for a second time between immediate post-test and follow-up test.

\section{Hence the following recommendations could be made: -}

1- Developing, planning, and implementing more training programs related to the diabetic elders care for non paramedical personnel.

2- Developing the outreach programs in Beni-Suef Governorate to promote the diabetic elders in the community according to their needs.

3- Encouraging the communities and NGO's (Non-governmental organizations) to establish local resources for the elderly care from all its aspects (physical, social, and psychological etc).

\section{References:}

1. Allender, J.A., \& Spradly, B.W. (2005): Community Health Nursing: Promoting and Protecting the Public's Health.( $6^{\text {th }}$ ed.): Lippincott Williams and Wilkins.

2. Friedman, S. (2006), In Meiner, S.E \& Lueckenotte, A.G. (2006): Integumentary functional. Gerontologic Nursing, $\left(3^{\text {rd }}\right.$ ed)., Mosby Elsevier,PP. 693- 728.

3. Central Intelligence Agency. (2007): The World Fact Book. Field listing-Age Structure. Updated 8 March 2007, from: "http// www. Cia. Gov/ pupulications/ fact book/ docs/ profileguide. Html."

4. Kaufmann, M.S. (2004): Changes of internal organ. Physiology of Aging. JAMA; 287(3): 337.

6. Kane, R.L., Ouslander, J.G., Abrass, I.B. \& Hill, M. (2004): Cardiovascular Disorders Essentials of Clinical Geriatrics (5 ${ }^{\text {th }}$ ed.) Library of Congress Cataloging-in- Publication Data, pp. 284-303

7. Stegman, J.K., Branger, E. \& Jacobs, A.E. (2005): Stedman's Medical Dictionary for the Health Professions and Nursing, (5 ${ }^{\text {th }}$ ed.): Lippincott Williams and Wilkins.

8. Paul Aoun, D.O., Charles, R., Alberecht, I. \& Gambert,S.R.(2005): Endocrinology: Diabetes Mellitus: Present and Future in a Continuing series of Articles on "Aspect of Diabetes Mellitus". The Clinical Journal of American Geriatrics Society; 13(6): 30-37.

9. Rivlin, P. (2003): Egypt's Demographic Challenges and Economic Responses. Middle East Review of International Affairs Journal ; 7(4): 1-12

9. Didammoni, M. (2008): Health Care of the Elderly Women in Egypt. Pro. The Ninth International Congress of Women's Health Issues. Faculty of Nursing, Alexandria University, 22-23 June.

10.Angelo, S. (2005): Medical Encyclopedia. Aging changes in the kidneys. A service of the US. National Library of Medicine and the National Institutes of Health. Yale School of Medicine.

11.Duthie, E.R. (2007): History and Physical Examination. In: Duthie EH, Katz PR, Malone ML, (Eds) Practice of Geriatrics. ( $4^{\text {th }}$ ed.) Philadelphia, PA: Elsevier Mosby; chap 1 .

12.Roach, S.S. (2010): Introductory Gerontological Nursing. Common Problems Affecting the Older Adult: Managing Common Physiologic Problems: Lippincott Williams \& Wilkins, 150-171. 
13.Minaker, KL., Common Clinical Sequelae of Aging. In: Goldman, L., Schafer, AI.,

(2011). (Eds). Goldman's Cecil Medicine. $\left(24^{\text {th }}\right.$ ed.) Philadelphia, PA: Elsevier Saunders;

2011:chap 24.

14.Kotb, S.A.M. (2004): Evalution of an Educational Program Among the Workers Working in Cement Faculty in Assiut City for Prevention of Occupational Hazards. Thesis, B.Sc., in Community Health Nursing, Assiut University.

15.S harkawy, S.A.E.H. (2007): Assessment of an Educational Program Concerning Nutritional Status Among the Elderly and Caregivers in rural area in Assiut Governorate. Thesis, B.Sc., in Community Health Nursing. Assuit University.

16.Kerrick, J.S. (1969): The use of Somantic Differentia: Its Special Application to Illness. Health Education Monograph; 29:3750.

17.Fathalla, M.F., \& Fathalla, M.M. (2004): A Practical Guide for Health Researchers. WHO Regional Publications, Eastern
Mediterranean Series 30: Regional Office for the Eastern Mediterranean, Cairo. P.96.

18.Towner, E.M. (2006): Assessment of Geriatric Knowledge: An Online Tool for Appraising Entering APN Students. Journal of Professional Nursing; 22 (2): 112-115.

19.Meiner, S.E. \& Lueckenotte, A.G. (2006): Gerontologic Nursing, ( $3^{\text {rd }}$ ed.): Mosby Elsevier.

20.Elkin, M.K., Perry, A.G., \& Potter, P.A. (2000): Nursing Interventions and Clinical Skills,: Mosby .

21.Imperio, K. \& Pusey-Reid, E. (2006). In Meiner, S.E and Lueckenotte, A.G. (2006):

Cognitive and neurological function. Gerontologic Nursing. ( $3^{\text {rd }}$ ed.): Mosby Elsevier, pp.

653- 692.

22. Ashley, M. and Ainlay, J.G. (2005):

Gerontology and Geriatrics Education: The Haworth Press. 
